\title{
Evaluación de tres productos desinfectantes sobre semillas de maíz y cebada para la producción en la tecnología de Forraje Verde Hidropónico
}

\author{
Andrés Zúñiga Orozco ${ }^{1}$, Ivette Beauregard Zúñiga ${ }^{2}$ \\ 1. Ingeniería Agronómica. UNED. CU San Carlos. Alajuela, Costa Rica; ivettebz@gmail.com. \\ 2. Ingeniería Agronómica. UNED. San Pedro, San José, Costa Rica; azunigao@uned.ac.cr
}

Recibido: 13 de setiembre de 2020 Aceptado: 03 de noviembre de 2020

Resumen

Introducción: EVALUACIÓN DE TRES PRODUCTOS DESINFECTANTES SOBRE SEMILLAS DE MAÍZ Y CEBADA PARA LA PRODUCCIÓN EN LA TECNOLOGÍA DE FORRAJE VERDE HIDROPÓNICO. Objetivo: analizar variables de crecimiento utilizando tratamientos desinfectantes de semillas, en diferentes dosis y en dos forrajes comúnmente usados para alimentación animal (maíz y cebada), haciendo uso de la tecnología FVH en la localidad de San Carlos, Alajuela, Costa Rica. Metodología: se usó los productos Kilol® (L DF-100 11 SL), Cloro (4\%) y Agua oxigenada (10\%) a una dosis $7.5 \mathrm{ml} / \mathrm{L}$ y $5 \mathrm{ml} / \mathrm{L}$, en dos tipos de forraje y se evaluaron las variables: producción de biomasa neta, materia seca (MS), proteína cruda e incidencia de hongos. Resultados: El mejor tratamiento para control de hongos fue el T6 (Agua oxigenada a 5ml/L) para cebada, en maíz no hubo diferencias. En producción de biomasa neta, el maíz acumuló mayor biomasa que cebada, siendo el T5 y T6 los que obtuvieron mayor peso y \% de proteína. En cuanto al contenido de materia seca, hay un efecto contraproducente al aplicar desinfectantes, puesto que todos acumularon menos materia seca con respecto al testigo, posiblemente debido a un efecto fitotóxico. La proteína cruda y materia seca en la cebada, supera el contenido de un alimento comercial para alimentación animal, el kilo de cebada es 3.85 veces más barato. Finalmente, se concluye que usar agua oxigenada a $5 \mathrm{ml} / \mathrm{L}$ es la mejor opción para desinfección de semilla, incluso con un efecto positivo al promover germinación, crecimiento y acumulación de biomasa neta. Conclusiones: todos los tratamientos tuvieron presencia de hongos saprófitos, pero el maíz fue el menos afectado y aunque en cebada se presentaron, no fueron especialmente importantes. El T6 (AO a $5 \mathrm{ml} / \mathrm{L}$ ) fue quien mejor controló hongos en cebada. Tanto en maíz como en cebada los tratamientos que presentaron valores más altos en producción de biomasa neta fueron el T5 (AO a 7.5 ml/L) y T6 (AO a $5 \mathrm{ml} / \mathrm{L}$ ). Tanto en maíz como en cebada, el tratamiento que presenta los valores más altos de materia seca fue el $\mathrm{T} 7$ (Testigo), pudo haber un efecto de fitotoxicidad en los demás tratamientos. Tanto en maíz como en cebada los tratamientos que presentaron valores más altos en proteína fueron el T5 (AO a 7.5 ml/L) en maíz y los T3, T5 y T6 en cebada. El agua oxigenada en dosis de $5 \mathrm{ml} / \mathrm{L}$ (T6), presentó los mejores efectos entre las variables analizadas y aunque en MS y proteína no fue así, se encuentra dentro de los valores recomendados para la alimentación animal, según diferentes autores. Además, presenta un efecto bioestimulante en germinación de semillas. Los resultados analizados en los FVH de esta investigación, demuestran tener mayor cantidad de proteína y materia seca que el alimento concentrado Vap Feed®.

Palabras clave: biomasa, fitotóxico, hidroponía, hongos, proteína

Abstract

EVALUATION OF THREE DISINFECTANT PRODUCTS ON CORN AND BARLEY SEEDS FOR PRODUCTION IN THE TECHNOLOGY OF HYDROPONIC GREEN FORAGE.

Objective: analyze growth variables using seed disinfectant treatments, in different doses and in two forages commonly used for animal feed (corn and barley), using the FVH technology in the locality from San Carlos, Alajuela, Costa Rica. Methodology: products like Kilol ${ }^{\circledR}(11 \mathrm{SL})$, Chlorine (4\%) and hydrogen peroxide (10\%) were used at a dose of $7.5 \mathrm{ml} / \mathrm{L}$ and $5 \mathrm{ml} / \mathrm{L}$, in two types of fodder and the variables evaluated were: production of net biomass, dry matter (MS), crude protein and fungal incidence. Results: the best treatment for fungal control was T6 (hydrogen peroxide at $5 \mathrm{ml} / \mathrm{L}$ ) for barley, in corn there were no differences. In net biomass production, corn accumulated the greater biomass than barley, with T5 and T6 being the ones with the highest weight and \% protein. As for the dry matter content, there is a counterproductive effect when applying disinfectants, since all accumulated less dry matter with respect to the control, possibly due to a 
phytotoxic effect. The raw protein and dry matter in barley, exceeds the content of a commercial food for animal feed, the kilogram of barley is 3.85 times cheaper. Finally, it is concluded that using hydrogen peroxide at $5 \mathrm{ml} / \mathrm{L}$ is the best option for seed disinfection, even with a positive effect by promoting germination, growth and accumulation of net biomass. Conclusions: All treatments had a presence of saprophytic fungi, but the corn was the least affected and although they were presented in barley, they were not especially important. The $\mathrm{T} 6$ (AO at $5 \mathrm{ml} / \mathrm{L}$ ) was the one who best controlled fungi in barley. In both corn and barley, the treatments that presented higher values in net biomass production were T5 (AO at 7.5 $\mathrm{ml} / \mathrm{L}$ ) and $\mathrm{T} 6(\mathrm{AO}$ at $5 \mathrm{ml} / \mathrm{L}$ ). In both corn and barley, the treatment with the highest values of dry matter was T7 (Witness), there could be a phytotoxicity effect in the other treatments. In both corn and barley, the treatments that presented higher values in protein were $\mathrm{T} 5$ (AO at $7.5 \mathrm{ml} / \mathrm{L}$ ) in corn and T3, T5 and T6 in barley. Oxygenated water in doses of $5 \mathrm{ml}$ / L (T6), had the best effects among the analyzed variables and although in MS and protein it was not, it is within the recommended values for animal feed, according to different authors. In addition, it has a biostimulant effect on seed germination. The results analyzed in the FVH of this investigation, demonstrate to have a greater amount of protein and dry matter than the concentrated food Vap Feed®.

Keywords: biomass, phytotoxicity, hydroponic, fungus, protein

\section{Introducción}

En la actividad pecuaria, es común observar a productores que venden su ganado bovino e incluso propiedades, debido a factores como la falta de financiamiento, bajos precios del mercado, altos costos de producción. La problemática aumenta conforme las consecuencias del cambio climático se van presentando; a nivel centroamericano la temperatura del aire incrementó un 0,9\% y las precipitaciones anuales bajaron un $10 \%$ (Stocker et al., 2013), estos factores así como las la acción del ser humano sobre el medio ambiente constituyen varias causas que provocan la degradación de los pastizales para la producción pecuaria y como consecuencia de ello, se reduce el rendimiento en área y biomasa vegetal, lo que implica el decrecimiento de la producción en animales (Álvarez, \& Febles, 2015). En Costa Rica y especialmente en época seca, la cantidad de forrajes que se producen no son suficientes o de la calidad mínima para una adecuada nutrición en animales de producción pecuaria, especialmente el ganado bovino por ser el de mayor importancia y cada vez más el problema se ve acentuado por el aumento en temperatura que produce el cambio climático (Hidalgo et al., 2017).

La calidad y los cuidados de los pastos son muy importantes para la producción pecuaria, ya que si no se tiene la cantidad y calidad necesaria en el momento que se requieran, se retrasa el desarrollo de los animales e incluso pueden llegar a enfermar. Un animal adulto de $400 \mathrm{~kg}$ de peso debe consumir $40 \mathrm{~kg}$ de forraje fresco diariamente y este debe tener al menos $7 \%$ de proteína y $50 \%$ de digestibilidad (Morales, 2006). Por otra parte, al haber grandes extensiones de deforestación y de mal manejo de fertilizantes en pasturas se incrementan los gases de efecto invernadero (GEIs) (Stocker et al., 2013), lo cual incide directamente en menos captura de $\mathrm{CO}_{2}$ y liberación de óxido nitroso a la atmosfera (Aymman et al., 2020). Debido a las situaciones citadas anteriormente, se necesitan soluciones que permitan a los productores tener el forraje en forma constante, barata y de alta calidad, puesto que el forraje es la fuente de alimentación más barata y de mejor aceptación por el sistema digestivo de los animales. Además, se debe tener en cuenta utilizar tecnología amigable con el ambiente y más eficiente, que lleve al productor a no depender de la incertidumbre del clima. Una solución para ésta problemática es el uso de la tecnología: forraje verde hidropónico $(\mathrm{FVH})$, ésta técnica permite en pocos días (9-15) obtener forraje verde y fresco con alto contenido proteico, muy palatable y con buena digestibilidad, además permite producir en cualquier época del año y localidad geográfica. Es inocuo, libre de enfermedades y de productos químicos, existe un considerable ahorro de agua, el espacio que se requiere para la producción es relativamente pequeño en comparación a sistemas tradicionales y sus costos de producción son bajos (Juárez et al., 2013, Rodriguez, 2003).

El FVH es una tecnología que se ha desarrollado en los últimos 30 años y busca solucionarle al productor la disponibilidad de forraje, tanto en cantidad como en calidad durante todo el año sin necesidad de depender del clima. Muchos son los sistemas que se han desarrollado, desde verticales, 
horizontales, en escalera, en invernadero, en galerones, con sustrato, entre otros. Los forrajes más utilizados son el maíz, alfalfa y cebada. El costo de producción de FVH, por concepto de superficie es 10 veces menor que el de una superficie para la producción de cualquier forraje en espacios abiertos, lo que se ejemplifica con el dato de que $75 \mathrm{~m}^{2}$ de producción de FVH tienen el equivalente de 3 ha de terreno agrícola para la producción de alfalfa (Alvarez, 2012), esa ventaja es debida a que el FVH puede ser instalado en forma modular en la dimensión vertical, lo que optimiza el espacio útil. Por otra parte, en la tecnología FVH el uso de maíz como fuente de alimentación es común a nivel mundial (Rivera et al., 2010), pero en condiciones tropicales no se acostumbra utilizar la cebada, por lo cual también se justifica valorar como otra opción de alimentación animal en este sistema, puesto que además se reporta con producciones de hasta $504 \mathrm{Kg}$ de materia fresca/día lo cual podría alimentar hasta 110 vacas en producción (Romero, Córdoba \& Gallardo 2009).

A pesar de ser una tecnología altamente eficiente tiene la desventaja de que requiere personal capacitado, un espacio donde poner la infraestructura, de preferencia contar con un sistema de riego automatizado y también tiene problemas con el desarrollo de hongos saprófitos en la semilla por exceso de humedad (Juárez et al., 2013), además de la aparición de larvas de Fungus gnat o dipteros de la familia Sciaridae, las cuales se comen las raíces tiernas en las bandejas de crecimiento. Los hongos saprófitos y las larvas de dípteros se aprovechan de la humedad y tienden a contaminar las bandejas, por lo cual deben ser controladas, para lo anterior se planteó el uso de algunos compuestos como tratamientos para desinfección de semilla. Para el control de enfermedades en etapa de semilla y en diferentes cultivos es común usar otro tipo de desinfectantes como el cloro (Romero, Córdoba \& Gallardo, 2009), yodo (Cortés-Flores et al., 2016), vinagre (Campos \& Manzano, 2007) y agroquímicos (Labrada \& Fornasari, 2001). En esta investigación se planteó el uso de otros compuestos tales como, un bactericida orgánico a base de extractos de semillas de cítricos, agua oxigenada y cloro; si bien es cierto, los productos citados son utilizados en el sector agrícola para la desinfección de bandejas de siembra, aplicaciones fitosanitarias y desinfección de herramientas, en la actualidad hay un vacío en el paquete tecnológico que se necesita implementar en la tecnología FVH, especialmente en la desinfección de semillas y en el ataque de larvas de díptera, factores que si no son bien manejados pueden deteriorar la calidad del forraje produciendo descenso en el $\mathrm{pH}$, compuestos fenólicos, ácido acético y alcoholes que no son recomendables para el sistema digestivo de los animales (Blanco, 1999).

El uso de extracto de semillas de cítricos (Puente et al., 2013), cloro (Romero, Córdoba \& Gallardo 2009) y agua oxigenada o peróxido de hidrógeno (Paniagua, 2018) se reportan con propiedades bactericidas, desinfectantes y hasta para limpieza de cintas de riego en explotaciones agrícolas, por lo cual, fueron valorados para esta investigación, también por su bajo costo y bajo impacto ambiental. El objetivo de este trabajo fue comparar tratamientos desinfectantes de semilla bajo diferentes dosis, en dos tipos de forraje y haciendo uso de la tecnología FVH con el fin de controlar hongos saprófitos y larvas de diptera. Para analizar el resultado y realizar las comparaciones correspondientes se midieron variables como la producción de biomasa, incidencia de hongos, materia seca y proteína.

\section{Materiales y Métodos}

Se preparó el invernadero de $16 \mathrm{~m}^{2}$, piso de concreto, sarán de $40 \%$ de sombra como paredes con 2.5 $\mathrm{m}$ de altura, verificando que no fuera accesible a agentes nocivos como pájaros y asegurando que estuviera en condiciones inocuas. Se usaron 16.8 kilos de semillas, correspondiente a $8.4 \mathrm{~kg}$ de semillas de cebada y $8.4 \mathrm{~kg}$ de semillas de maíz. Para cuantificar la presencia de hongos, se realizó una escala de severidad del 1-5\% (donde 1 es el valor mínimo y 5 el valor máximo).

Los estantes (orientación de norte a sur), el riego, el crecimiento, la cantidad de semilla, el rendimiento, entre otros. De esta primera experiencia se determinó que había que cambiar la 
orientación de los estantes (de este a oeste) para favorecer la entrada de luz y usar una menor densidad de semilla puesto que, muchas quedaban sin germinar en el fondo de la bandeja. Para la germinación de las semillas se utilizó bandejas de aluminio rectangulares desechables $(52 \times 32 \mathrm{~cm})$, las bandejas se colocaron en estructuras de soporte de madera curada con dimensiones de $1 \mathrm{~m}$ de acho x $3 \mathrm{~m}$ de largo, usando como estantes láminas de zinc lisas perforadas cada $20 \mathrm{~cm}$ para el drenaje del lixiviado de riego. Se utilizaron cuatro niveles, con $50 \mathrm{~cm}$ de altura entre los niveles. Para el riego se utilizó manguera común de $3 \mathrm{~mm}$ de espesor. Las semillas usadas fueron para maíz (var. Rocame amarillo) y semillas de cebada (Grado comercial). Los insumos utilizados para la desinfección de semillas fueron: extractos de semillas de cítricos (Kilol® L DF-100 11 SL), agua oxigenada o peróxido de hidrógeno al $10 \%$, cloro al $4 \%$ y agua potable, los cuales fueron utilizados en dosis de 5 y $7.5 \mathrm{ml} / \mathrm{L}$. Para medir la variable de peso se utilizó una balanza marca Maxi House (cap. máx. de 30 kg).

Se realizó una desinfección de las semillas de maíz y cebada en bandejas separadas. Se tomaron 8.4 $\mathrm{kg}$ de cada semilla y se dividieron en 7 partes iguales de $1.2 \mathrm{~kg}$ para poner en las bandejas. Se introdujeron en baldes, se aplicó $3 \mathrm{~L}$ de agua y se aplicaron los respectivos productos desinfectantes en inmersión, en una relación de $5 \mathrm{ml}$ o $7.5 \mathrm{ml}$ por litro de agua. Se dejaron en imbibición las semillas durante 12 horas en su respectiva bandeja, cada una fue identificada con su respectivo nombre.

Una vez cumplido el punto anterior, se procedió a secar las semillas eliminando por completo el agua de las bandejas. Se distribuyeron las semillas de manera uniforme en ( $0.4 \mathrm{~kg}$ por bandeja), según el tratamiento y dosis, con una altura de espesor no mayor a $1 \mathrm{~cm}$ para que éstas pudieran germinar efectivamente y sin quedar en el fondo.

Diariamente se verificó la humedad de las semillas en las bandejas, revisando manualmente el contenido de agua, de tal forma que el criterio de riego fue regar diariamente a excepción que hubiera exceso de agua en el fondo de las bandejas por encima de $1 \mathrm{~cm}$. Cuando las semillas germinadas formaban una alfombra, ésta se levantaba cada día, con el fin de observar no solo el nivel de agua en la base de la bandeja sino también de monitorear la presencia de hongos o moho. Durante el ensayo, se aplicó $500 \mathrm{ml}$ de agua dos veces al día para un total de $1000 \mathrm{ml}$ por bandeja. Conforme avanzaban los días y se desarrollaban las plántulas, se disminuyó el riego a 250-300 ml, dos veces al día (500$600 \mathrm{ml}$ diarios), esto se hizo a partir del día 7. Luego, a partir del día 7 hasta el 10, se aplicaron 300 $\mathrm{ml}$ de agua una vez por día. Finalmente, a partir del día 11, no se hizo riego y las plantas fueron cosechadas el día 12. Al día 12 se tomaron las muestras para los análisis y se realizaron las mediciones correspondientes.

Las variables cuantificadas fueron: ganancia de biomasa neta(g), incidencia de hongos (escala de severidad 1-5, siendo 1 poca afectación y 5 la mayor afectación), cantidad de materia seca y de proteína (g). Se cosechó cada una de las bandejas, se pesó la producción de biomasa por tratamiento y se cuantificó la incidencia de hongos. Una vez pesadas, se registraron los datos y se introdujeron en bolsas plásticas respectivamente identificadas para ser enviadas luego al laboratorio y determinar otras variables como la materia seca y contenido de proteína de cada uno de los tratamientos. Se realizó comparación de resultados con esta tecnología versus un alimento comercial (Vap Feed®) 
Cuadro 1. Tratamientos utilizados en maíz y cebada como desinfectantes de semilla.

\begin{tabular}{|c|l|c|}
\hline Tratamiento & \multicolumn{1}{|c|}{ Producto } & Dosis (ml/L) \\
\hline $\mathbf{1}$ & Extracto de semilla de cítricos & 7.5 \\
\hline $\mathbf{2}$ & Extracto de semilla de cítricos & 5 \\
\hline $\mathbf{3}$ & Cloro (4\%) & 7.5 \\
\hline $\mathbf{4}$ & Cloro (4\%) & 5 \\
\hline $\mathbf{5}$ & Peróxido de hidrógeno (10\%) & 7.5 \\
\hline $\mathbf{6}$ & Peróxido de hidrógeno (10\%) & 5 \\
\hline $\mathbf{7}$ & Testigo (sin aplicación) & - \\
\hline
\end{tabular}

En cuanto al diseño del experimento se utilizó un diseño experimental irrestricto al azar donde la unidad de medición aleatoria fue cada bandeja de siembra y se realizaron 3 repeticiones por tratamiento. La población muestreada fueron 21 bandejas. Para el análisis de los datos se realizó un ANOVA y una prueba de Tukey para comparación entre medias con un error experimental de $\mathrm{p}=0.05$. Se utilizó el software estadístico MINITABß para el procesamiento de los datos.

\section{Resultados}

En la variable biomasa neta, se observan diferencias significativas ( $p$-valor $<0.05$ ) entre los tratamientos. Al analizar las medias (Figura 1), usar agua oxigenada tanto a 5 como a $7.5 \mathrm{ml} / \mathrm{L}$ es beneficios para la variable ganancia de biomasa neta. El agua oxigenada a $5 \mathrm{ml} / \mathrm{L}$ presentó: $1130 \mathrm{gr}$ (maíz) y 595 gr (cebada), y para con $7.5 \mathrm{ml} / \mathrm{L}: 1073.3$ gr (maíz) y 621.7 gr (cebada)

A continuación, se describen las variables analizadas iniciando por la ganancia de biomasa neta (g)

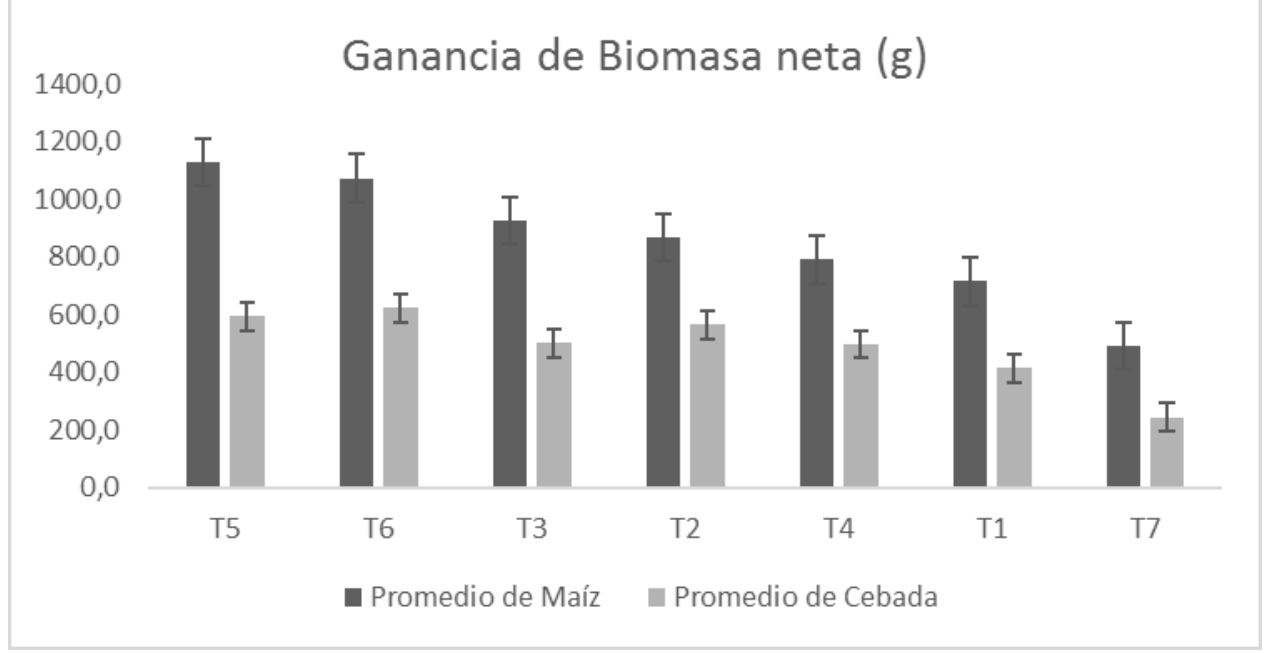

Figura 1. Ganancia de Biomasa neta para dos forrajes en sistema de FVH, según tratamiento.

Se observa más claro la ganancia de biomasa en maíz que en cebada. El maíz muestra mayor capacidad de producir biomasa en 12 días con respecto a la cebada. En términos generales el maíz presenta una media de $856.4 \mathrm{~g}$ y la cebada $490.5 \mathrm{~g}$ en cuanto a ganancia de biomasa neta. 


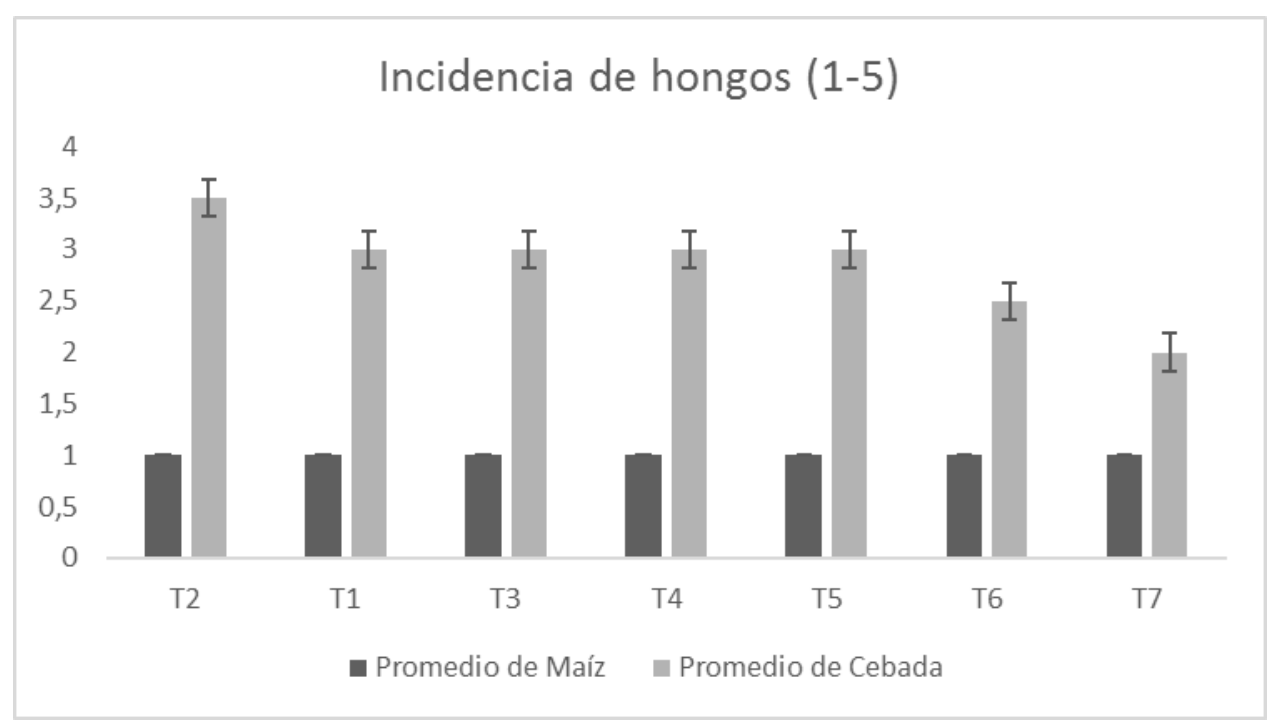

Figura 2. Incidencia de hongos bajo una escala de severidad (1-5) para dos forrajes en sistema de FVH.

Para la variable, incidencia de hongos (Figura 2), hubo diferencias significativas en cebada (pvalor $<0.05$ ), mientras en maíz no hubo diferencias significativas. Se determina un promedio de severidad de 1 en maíz y 2.86 en cebada (se utilizó una escala de severidad de 1-5, siendo 5 la de mayor afectación). Como se observa en la figura, para el cultivo de cebada, el tratamiento con extracto de semillas de cítricos en $5 \mathrm{ml} / \mathrm{L}$ (mencionar el número de tratamiento entre paréntesis), fue el mayormente afectado, presentando un promedio de 3.5 según la escala, mientras que el tratamiento testigo y con agua oxigenada a $5 \mathrm{ml} / \mathrm{L}$ presentaron el menor daño (idem).

Se observa claramente que la cebada es más susceptible a ser afectada por hongos saprófitos (Figura 2). En maíz, todos los tratamientos presentaron un promedio de severidad en la escala 1 de daño, por lo que no se observaron diferencias entre aplicar o no desinfectantes.

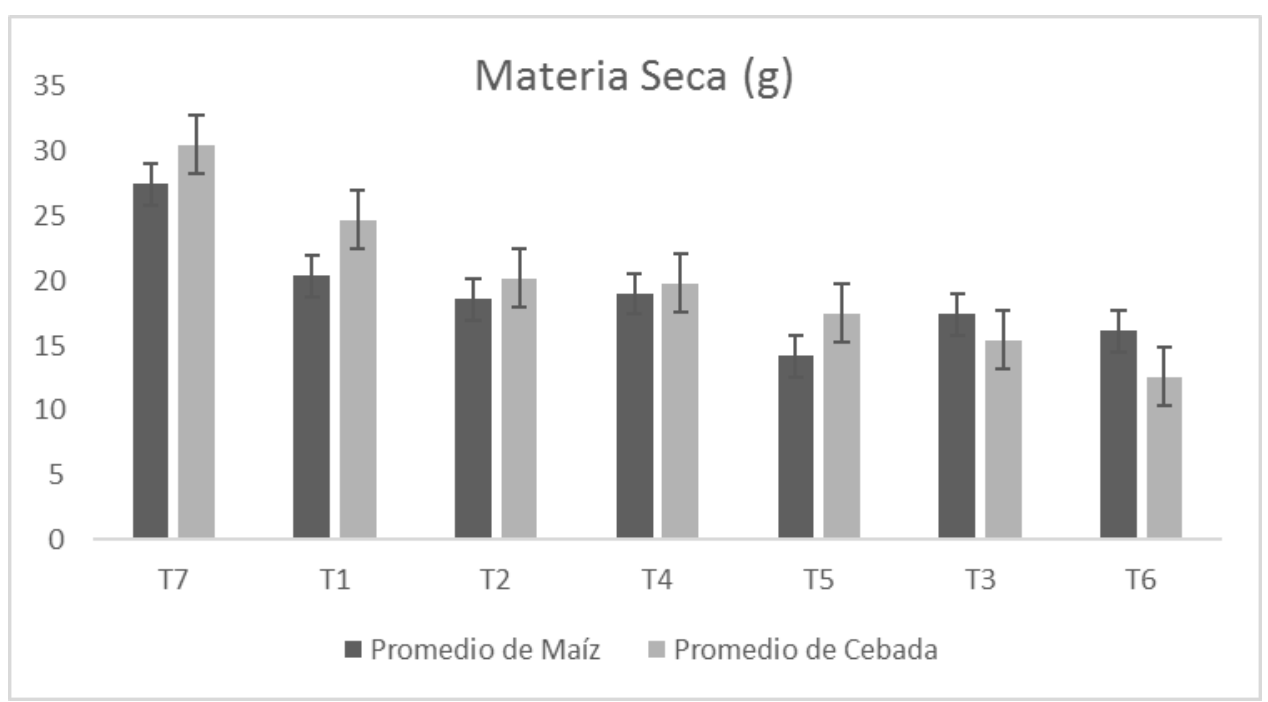

Figura 3. Cantidad de materia seca (g) para dos forrajes en sistema de FVH, por tratamientos. 
La figura anterior, muestra que, tanto en cebada como en maíz, las mayores cantidades de materia seca se presentaron en el testigo y en el tratamiento con extracto de semillas de cítricos a una dosis de 7.5 cc/L (IDEM) (p-valor $<0.05)$. La reducción en materia seca comparando los tratamientos con el testigo se discutirá más adelante.

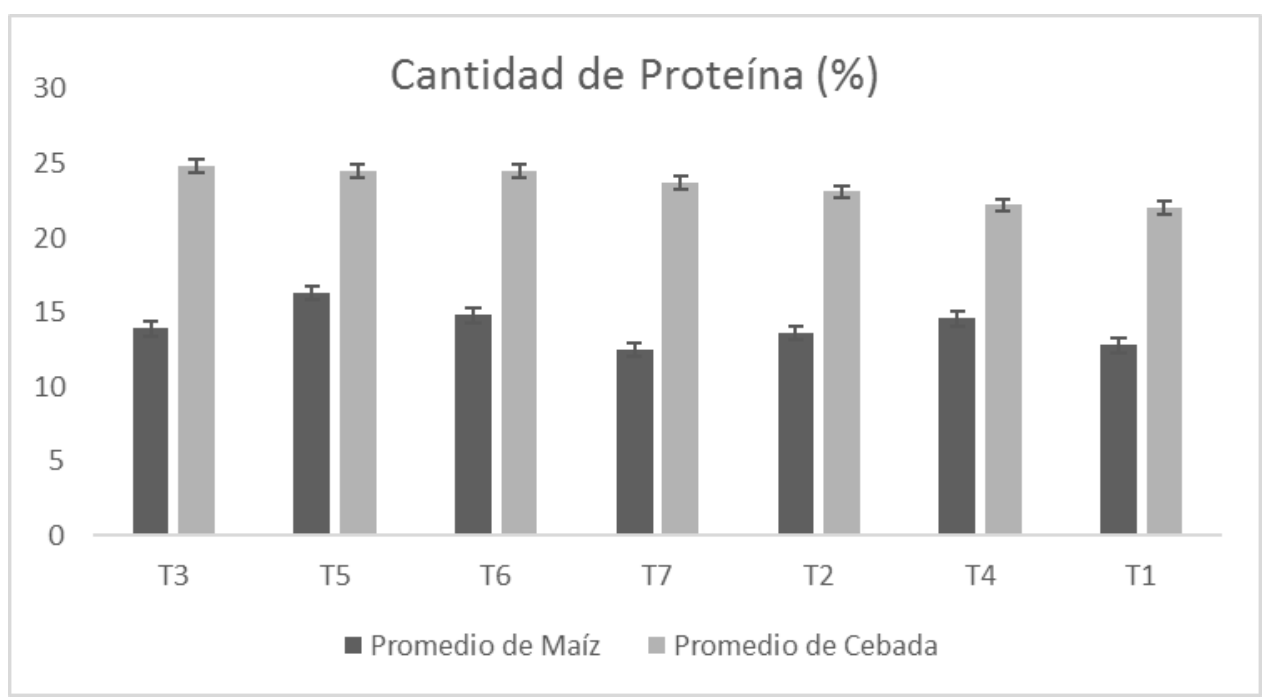

Figura 4. Cantidad de proteína (\%) para dos forrajes en sistema de FVH.

Con respecto a la figura 4, se evidencia que la cebada es la que obtiene mayor cantidad de proteína a nivel general en todos los tratamientos. En cantidad de proteína para maíz, los tratamientos con agua oxigenada en 5 y $7.5 \mathrm{ml} / \mathrm{L}$, obtuvieron la mayor cantidad. En cebada el agua oxigenada en $7.5 \mathrm{ml} / \mathrm{L}$ junto al cloro a la misma dosis, fueron los mejores tratamientos para esta variable.

Cuadro 2. Comparación de resultados obtenidos con la tecnología FVH para las variables materia seca (MS) y proteína cruda (PC) vrs. alimento comercial.

\begin{tabular}{l|c|c|c}
\hline \multirow{2}{*}{$\begin{array}{c}\mid \\
\text { Variable }\end{array}$} & \multicolumn{2}{|}{} \\
\hline MS (materia seca) & $\begin{array}{c}\text { Alimento } \\
\text { Vap Feed }{ }^{\circledR}\end{array}$ & FVH \\
\cline { 3 - 4 } & $13 \%$ & $20.1 \%$ & Maíz \\
\hline PC (proteína cruda) & $16 \%$ & $23.5 \%$ & $19.0 \%$ \\
\hline
\end{tabular}

Cuadro 3. Comparación de costo de producción (\$) por kilo utilizando maíz y cebada con la tecnología FVH vrs. alimento comercial.

\begin{tabular}{l|c|c|c}
\hline Variable & $\begin{array}{c}\text { Alimento } \\
\text { Vap Feed }{ }^{\circledR}\end{array}$ & Cebada & Maíz \\
\hline Proteína cruda & $16 \%$ & $23.5 \%$ & $14.1 \%$ \\
\hline Costo por kilo & $\$ 0.4$ & $\$ 0.1$ & $\$ 0.2$ \\
\hline
\end{tabular}

Para las variables Materia Seca (MS) y Proteína Cruda (PC) se tomó como referencia el alimento comercial Vap Feed $®(1$ saco de 23 kilos $=\$ 9.1)$ por ser de uso común en el sector pecuario y se hizo una comparación entre los resultados obtenidos en el sistema FVH con maíz y cebada en promedio (Cuadros 2 y 3), respecto al concentrado comercial. Para esto se tuvo que transformar las variables de materia seca y proteína, de gramos a porcentajes. Después de realizar la comparación de cada uno 
de ellos, se evidencian mejores contenidos de materia seca y proteína en maíz y cebada usando el sistema FVH en comparación con el alimento comercial. Además, se hizo la comparación económica en cuanto a la variable, producción por kilo, siendo más barato producir cebada y maíz en FVH en comparación de darle al animal el alimento comercial Vap Feed®

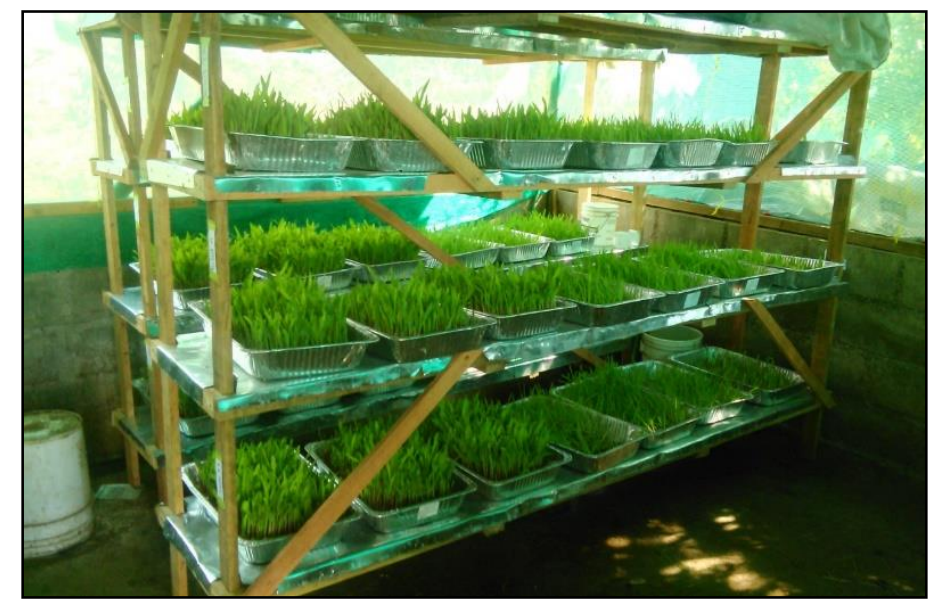

Figura 5. Muestra visual del experimento ejecutado. Orientación de bandejas (E-O). Maíz (izquierda), Cebada (derecha). Edad 9 días. Ciudad Quesada, Alajuela, Costa Rica. Marzo 2017.
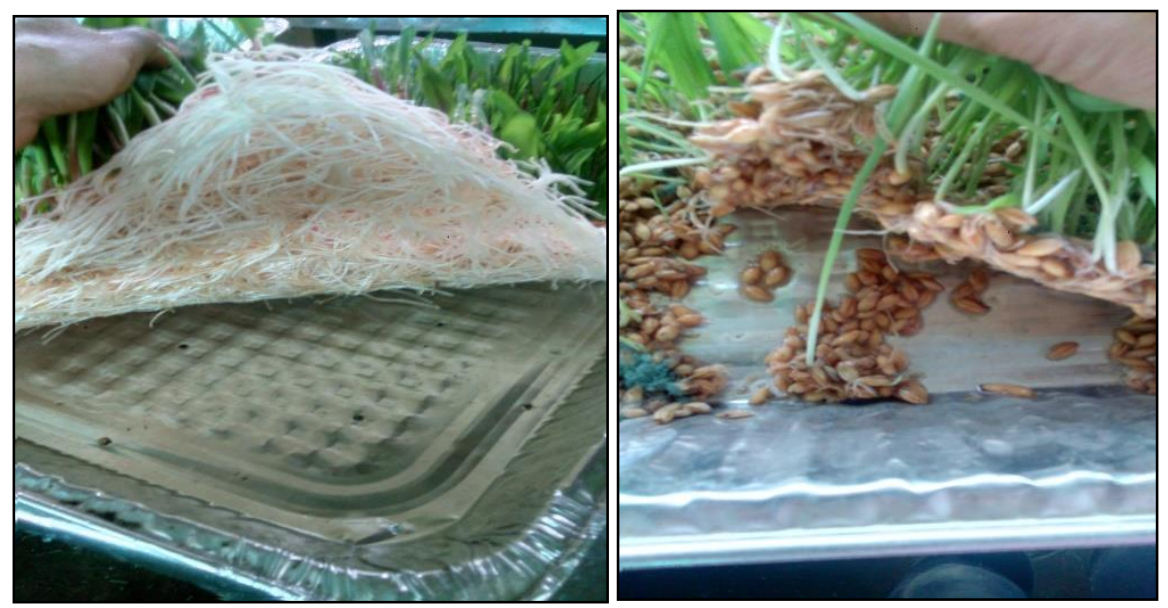

Figura 6. Alfombra de maíz (izquierda) y de cebada (derecha). Edad 12 días. Ciudad Quesada, Alajuela, Costa Rica. Abril 2017.

\section{Discusión}

Las plantas de maíz se vieron más favorecidas en el desarrollo de biomasa (alcanzando una media de $856.4 \mathrm{~g}$ ) y menor incidencia de hongos (1, según la escala de severidad), mientras que, en las plantas de cebada, aunque su crecimiento fue óptimo $(30 \mathrm{~cm}$ o más) y su contenido de proteína fue muy superior (23.5\%), no se produjo tanta biomasa (490.5 g como media) en comparación con el maíz, además la incidencia de hongos fue mayor alcanzando un $2.86 \%$ según la escala de severidad utilizada (Figura 1 y 2). La cebada al ser una planta $\mathrm{C}_{3}$ y tener una exposición más directa con los rayos solares (debido a la posición de bandejas y estantes), es posible que fuera más vulnerable a este factor y su metabolismo fue afectado, lo cual se refleja en los resultados mencionados (figuras 1,2 y 4). De acuerdo con Lara, Drincovich \& Andreo (2011), las plantas $C_{3}$ son muy competitivas en climas templados y húmedos, pero esta característica les dificulta su existencia en lugares con altas 
temperaturas e intensidad lumínica. Lo que pudo reflejarse en los resultados vistos en la cebada respecto a ganancia de biomasa, incidencia de hongos y cantidad de materia seca.

Los tratamientos en la figura 1, muestran que el agua oxigenada en ambas dosis, son los que presentan mayor cantidad de biomasa neta producida. Respecto al agua oxigenada o peróxido de hidrógeno, como desinfectantes de semillas para $\mathrm{FVH}$, no se registró ninguna investigación previa relacionada, sin embargo, sí existen datos del uso de los mismos para desinfección en cultivos como lechuga, en donde se hace una comparación de la eficiencia entre el agua oxigenada y cloro, los mejores resultados se presentan con el uso de agua oxigenada al 3 y $4 \%$ (Ramón-Avalos, Rosas-Acevedo \& Vargas-Román 2016), lo cual concuerda con los datos obtenidos en ésta investigación.

Sobre los productos utilizados y variables analizadas, otras investigaciones han obtenido que el cloro comercial (2\%) es de buen uso en desinfección de semillas (Romero, Córdoba \& Gallardo, 2009 y Salazar, 2005) sin embargo en esta investigación no fue mejor que el peróxido de hidrógeno. En otros casos por ejemplo las semillas desinfectadas con hipoclorito de sodio al $2 \%$ pueden causar daño de los tejidos y reducción de la germinación (Billard, Dalzotto \& Lallana, 2014). Sobre el extracto de semillas de cítricos tiene diversas aplicaciones sin embargo siempre enfocadas en tratamientos fitosanitarios en campo y en labores poscosecha, por ejemplo Latour (2013), realiza un estudio para evaluar la calidad sanitaria de los alimentos, en donde evalúa la eficacia de este producto en el control de Escherichia coli y Staphylococcus aereus, donde indica que la acción antibacteriana del mismo, resulta ser mayor al aumentar la concentración, lo cual se confirma en este estudio, sin embargo solo se usaron dos dosis y no fue mejor que el peróxido de hidrógeno bajo éstas condiciones experimentales.

En cuanto al maíz, todos los tratamientos presentaron un índice de 1 en cuanto a la incidencia de hongos, sugiriendo que, en el caso de este cultivo, no es necesario desinfectar la semilla. Para el caso de la cebada, aunque el tratamiento testigo obtuvo menor cantidad de hongos, se puede escogerse el agua oxigenada a $5 \mathrm{ml} / \mathrm{L}$ por obtener el segundo valor de control y porque, además, como se vio en la acumulación de proteína y biomasa, mejora la cantidad de las mismas y además es de bajo costo e impacto ambiental. Analizando las variables ganancia de biomasa (figura 1) e incidencia de hongos (figura 2), se observa que el agua oxigenada en dosis de $5 \mathrm{ml} / \mathrm{L}$, obtiene mayor cantidad de biomasa y menor incidencia de hongos, además es el tratamiento que acumula mayor contenido de proteína después del otro tratamiento con agua oxigenada a $7.5 \mathrm{ml} / \mathrm{L}$ (figura 4), por lo cual se convierte en el mejor tratamiento para desinfección de semillas en este tipo de sistemas hidropónicos.

Entre los factores que posiblemente favorecieron la incidencia de hongos, principalmente en la cebada, se puede mencionar el riego. Esta investigación se realizó en el mes de abril, correspondiendo a la estación seca, en donde se presentaron temperaturas entre los $28-30^{\circ} \mathrm{C}$. Al suministrarle agua diariamente, posiblemente causó un microclima favorable para los hongos, por lo que analizar este aspecto es muy importante para próximas investigaciones. En este caso, se utilizó riego en dosis de entre los 250-500 $\mathrm{mL}$ y aunque las bandejas tenían varias perforaciones para el drenaje del agua siempre hubo presencia de hongos saprófitos y mohos. Según Juárez et al. (2013), el riego por inundación causa asfixia radicular, estrés, ataque de hongos y pudriciones que pueden ocasionar la pérdida total del cultivo. Aunque el riego no se hizo por inundación, lo que recomiendan estos autores es hacerlo a través de micro aspersores, nebulizadores o bomba aspersora portátil de manera uniforme, los cual brinda mejores resultados y reduce la presencia de hongos.

Cuando se menciona la presencia de hongos en los alimentos comúnmente se hace referencia a micotoxinas, sin embargo, este tipo de hongos no se han encontrado en cultivos bajo la técnica de FVH. Prince (2014) reporta la presencia de hongos del género Rhyzopus y Aspergillus. Según Arauz (2011), los hongos saprófitos ayudan al reciclaje de la materia orgánica, liberando nutrientes que 
enriquecen el suelo y sirven como alimento a organismos del suelo como microartrópodos y lombrices, por lo tanto, no provocan daños. Otros investigadores reportan otros métodos de control de hongos saprófitos en producción de FVH, por ejemplo, Carballo (2005), sugiere utilizar yodo con urea y aplicar a las semillas mediante el riego. Prince (2014) reporta el uso de cal, hipoclorito de sodio (4\%) y ozono, siendo este último el más eficaz, también en este investigador reporta que el hipoclorito de sodio (4\%) no fue el mejor tratamiento, lo cual concuerda con lo obtenido con los datos recolectados en la presente investigación.

En relación con la materia seca (MS), la figura 3 indica que, la cebada tuvo una media de $20.1 \mathrm{gr}$, mientras que el maíz obtuvo un 19.03 gr, lo cual según Barahona (2015) son favorables para alimentación de ganado bovino. Tanto en cebada como en maíz, las mayores cantidades se presentaron al usar extracto de semillas de cítricos en dosis de $7.5 \mathrm{ml} / \mathrm{L}$, obteniéndose en maíz: 20.4 gr y para cebada: 24.7 gr, y en el testigo, obteniéndose para maíz: 27.5 gr y para cebada: 30.5 gr. Aunque en el testigo, para la variable MS se acumuló mayor contenido con respecto a los demás tratamientos, este efecto posiblemente se deba a un factor de fitotoxicidad y se debe aclarar que, el testigo no puede verse como un buen tratamiento puesto que, también obtuvo la menor ganancia de biomasa neta para ambos forrajes (figura 1).

Referente al análisis de proteína (figura 4 y cuadro 2) se obtiene en el maíz una media de $14.1 \%$ y en cebada $23.5 \%$, lo cual se adapta a lo reportado por Lobo \& Díaz (2008) y Barahona (2015), donde los contenidos deben estar entre $14-20 \%$, esto hace que los dos forrajes se conviertan en excelentes fuentes de proteína, igualando e incluso superando los contenidos de algunos concentrados comerciales para alimentación de ganado bovino. Además, con un contenido bastante bueno de materia seca como se puede observar en el cuadro 2 donde el promedio es de $20.1 \%$ en cebada y $19.0 \%$ en maíz. Los tratamientos que alcanzaron mayor contenido de proteína fueron a los que se aplicaron el agua oxigenada a una dosis de $7.5 \mathrm{ml} / \mathrm{L}$, donde el maíz alcanzó el $16.3 \%$ y el cloro a una dosis de $7.5 \mathrm{ml} / \mathrm{L}$, donde el contenido de proteína en cebada, alcanzó el $24.8 \%$. Los datos obtenidos en proteína permiten confrontarlos con los datos de alimentos comerciales como el Vap Feed® para vacas lecheras (cuadro 2 y 3 ), el cual posee un $16 \%$ de proteína cruda, de manera que los forrajes usados tienen valores dentro de este rango e incluso superiores, por lo tanto, los forrajes producidos bajo este sistema y con los tratamientos de semilla utilizados se convierten en una buena opción de producción.

Con base en todos los análisis realizados en este trabajo, es apreciable que el agua oxigenada en las dosis utilizadas $(7.5 \mathrm{ml} / \mathrm{L}$ y $5 \mathrm{ml} / \mathrm{L})$, obtuvieron diferencias significativas con respecto a los otros tratamientos en la mayoría de las variables ( $p$-valor $<0.05$ ), posicionándose entre los mejores resultados (se adjunta la Fig. 4). Debido a su bajo costo, fácil adquisición y bajo impacto ambiental, resulta atractiva como desinfectante de semillas en la técnica de producción FVH. Bravo et al. (2010) señala que, obtener buenos rendimientos con bajos costos utilizando tecnologías modernas, es lo que les permite a los productores competir en forma eficiente. Además, con el análisis de proteína y materia seca, queda demostrado que los forrajes cumplen con los parámetros mínimos de calidad para la alimentación de ganado bovino y puede ser usado en otros animales.

En cantidad de proteína para maíz, los tratamientos con agua oxigenada en 5 y $7.5 \mathrm{ml} / \mathrm{L}$, obtuvieron la mayor cantidad. En cebada el agua oxigenada en $7.5 \mathrm{ml} / \mathrm{L}$ junto al cloro a la misma dosis, fueron los mejores tratamientos para esta variable. Adicionalmente, hubo un efecto de carácter bioestimulante con el uso del agua oxigenada que no estaba contemplado dentro del diseño pero con los resultados obtenidos se logró observar, en otras investigaciones como las de Barba-Espín et al. (2010), Valls \& Sáenz (2015) y Hernández \& Sanchez (2018) mencionan que, el peróxido de hidrógeno o agua oxigenada, estimula la germinación y el crecimiento temprano de las plántulas, acción que se correlaciona con la disminución de los niveles endógenos de ABA y la inducción de 
proteínas que se relacionan con la señalización, desarrollo, división y elongación celular, así como el control del ciclo celular. Este fenómeno fue notorio en la producción de biomasa, en donde las bandejas que fueron sometidas a los tratamientos con agua oxigenada obtuvieron los mejores resultados. De igual forma, el contenido de proteína para estos tratamientos fue de los valores más altos y controló mejor los hongos saprófitos.

La técnica de FVH es una excelente alternativa para la alimentación de los animales debido al mayor contenido de proteína con respecto al señalado en los alimentos concentrados, por lo que su utilización se hace relevante en las explotaciones pecuarias, además la técnica de FVH no depende de las condiciones ambientales y la uniformidad de la calidad del producto es mejor al tenerlo en condiciones controladas. Por otra parte, con esta investigación se puede solventar el problema del manejo fitosanitario de semilla al controlar hongos y larvas de díptera usando agua oxigenada en las dosis indicadas, además con el uso de este compuesto obtener un efecto bioestimulante que les ayudará a los forrajes a crecer de buena forma.

\section{Agradecimientos}

A la agencia de extensión del Ministerio de Agricultura y Ganadería (MAG) de San Carlos,

Alajuela y a la empresa privada GRUPO CRECE S.A.

\section{Referencias}

Alvarez, F. (2012). Manual de producción de Forraje verde hidropónico: una alternativa para alimentación de animales en periodos de carencia de pastos. Lima, Perú: Editorial Servicios Generales.

Álvarez, A. \& Febles, G. (2015). El cambio climático y su vinculación los pastos y forrajes en Cuba. Ponencia en el V Congreso Internacional de Producción Animal Tropical. Habana, Cuba.

Arauz, L. (2011). Fitopatología: un enfoque agroecológico. II Edición. San José, Costa Rica: Editorial de la Universidad de Costa Rica.

Aymman, C., Neftel, A., Jocher, M., Fuhrer, J. \& Leifeld, J. (2020). Effect of management and weather variations on the greenhouse gas budget of two grasslands during a 10-year experiment. Agricult. Ecosist. Environment. 292, UNSP: 106814. DOI: 10.1016/j.agee.2019.106814

Barahona, R. (2015). Manejo de forrajes tropicales. Ponencia en el Congreso Nacional Lechero. Cámara Nacional de Productores de Leche. San José, Costa Rica.

Barba-Espín, G., Diaz-Vivancos, P., Clemente-Moreno, M. J., Albacete, A., Faize, L., Faize, M., Pérez-Alfocea, F. \& Hernández, J.A. Interaction between hydrogen peroxide and plant hormones during germination and the early growth of pea seedlings. Plant Cell Environm., 33, pp. 981-994.

Bilard, C. E., Dalzotto, C. A. \& Lallana, V. H. (2014). Desinfección y siembra de asimbiótica de semillas de dos especies y una variedad de orquídeas del género Oncicium. Polibotánica, 38, pp. 145-157. 
Blanco, M (1999). El alimento y los procesos digestivos en el rumen. Sitio Argentino de Producción Animal. Departamento de Producción Animal. Universidad Nacional de Rio Cuarto. Córdoba, Argentina. Recuperado de: http://www.produccionanimal.com.ar/informacion_tecnica/manejo_del_alimento/70-alimentos_rumen.pdf

Bravo, M., Lambretón, V. \& Márquez, H. (2010). Introducción a las Finanzas. IV Edición. Monterrey, México: Editorial Pearson, Prentice Hall.

Campitelli, P. \& Ceppi, S. (2008). Chemical, physical and biological compost and vermicompost characterization: A chemometric study. Chemometrics and Intelligent Laboratory Systems, 90(1), pp. 64-71.

Campos, M.A. \& Manzano, W. (2007). Evaluación de métodos de desinfección de hortalizas que se consumen en crudo (Tesis de pregrado). Universidad de El Salvador.

Carballo, C. (2005). Manual de procedimientos para la producción de forraje verde hidropónico. EcoAgro, boletín técnico. Recuperado de: http://200.26.174.77/assets/repositorioPdfs/DOAGN-CONALE-0037.pdf

Cortés-Flores, C., Rodriguez-Mendoza, M., Benavides-Mendoza, A., García-Cue, J., TorneroCampante, M., \& Sánchez-García, P. (2016). El yodo aumenta el crecimiento y la concentración de minerales en plántulas de pimiento morrón. Agrociencia, 50(6), pp. 747758.

Hachicha, R., Rekik, O., Hachicha, S., Ferchichi, M., Woodward, S., Moncef, N.,... Mechichi, T. (2012). Co-composting of spent coffee ground with olive mill wastewater sludge and poultry manure and effect of Trametes versicolor inoculation on the compost maturity. Chemosphere, 88(6), pp. 677-682.

Hernández, L. \&Sánchez, D. (2018). Utilización de peróxido de hidrógeno para mejorar el crecimiento de plantas en condiciones salinas. IDIES: IDIES: I+D en Institutos de Educación Superior. Recuperado de: file:///C:/Users/Andres\%20Z\%C3\%BA\%C3\%B1iga\%20Orozco/Downloads/p36 2018 pero xido plantas salinas.pdf

Hidalgo, H. G., Alfaro, E. J. \& Quesada-Montano, B. (2017). Observed (1970-1999) climate variability in Central America using a high-resolution meteorological dataset with implication to climate change studies. Climatic Change, 141(1), pp. 13-28.

Juárez, P., Sandoval, M., Juárez, C. \& Alejo G. (2013). Producción de forraje verde hidropónico. Revista Fuente Nueva Época, 4(13), pp. 16-26.

Labrada, R. \& Fornasari, L. (2001). Global Report on Validated Alternatives to the Use of Methyl Bromide for Soil Fumigation. FAO Plant Production and Protection Paper, 166. Recuperado de: http://www.fao.org/3/y1809e00.htm

Langtry, A., Martín, L. \& Merino, J. (2011). Características plantas $C_{3}, C_{4}$ y CAM. Dos metabolismos fotosintéticos con un mismo destino. Recuperado de: http://www3.uah.es/pedrovillar/Docencia/Ecologia\%20Grado\%20Biologia/Archivos/Semin arios/C3,\%20C4,\%20CAM/Langtry,\%20Martin,\%20Merino.pdf

Lara, M. V., Drincovich, M. F. \& Andreo, C. (2010). Transiciones metabólicas en la fijación fotosintética el carbono en plantas del género Portulaca. Buenos Aires, Argentina: Editorial CONICET. 
Latour, L. (2013). Eficacia de un desinfectante biodegradable a base de cítricos en el control de Escherichia coli y Staphylococcus aereus (Tesis de pregrado). Universidad Nacional del Centro del Perú, Perú.

Lobo, M. \& Díaz, O. (2008). Agrostología. San José, Costa Rica. Editorial: EUNED.

Morales, G. (2006). Rol de los forrajes y los suplementos en la producción de leche bajo pastoreo. Alcances Tecnológicos, 10(1), pp. 45-54.

Prince, R. (2014). Evaluación de la eficiencia en el control del hongo en FVH mediante el uso de productos químicos (Tesis de pregrado). Universidad Autónoma Agraria Antonio Narro, Unidad Laguna, División Regional de Ciencia Animal. Coahuila, México.

Ramón-Avalos, S., Rosas-Acevedo, J. L. \& Vargas-Román, W. E. (2016). Eficiencia desinfectante del peróxido de hidrógeno al 3 y $4 \%$ en el lavado de lechuga romana (Latuca sativa L.). Investigación y Desarrollo en Ciencia y Tecnología de Alimentos, 1(1), pp. 146-150.

Rivera, A., Moronta, M., González-Estopiñán, M., González, D., Perdomo, D., García, D. E., Hernández, G. (2010). Producción de forraje verde hidropónico de maíz (Zea mays L.) en condiciones de iluminación deficiente. Zootecnia Tropical, 28, pp. 33-41.

Rodriguez, A. C. (2003). Cómo producir con facilidad, rapidez y óptimos resultados forraje verde hidropónico. Mexico, D.F.: Editorial Diana.

Romero, M., Córdoba, G. \& Gallardo, E. (2009). Producción de forraje verde hidropónico y su aceptación en ganado lechero. Acta Universitaria, 19(2), pp. 11-19.

Stocker, T.F. et al. (2013). Climate Change 2013: The Physical Science Basis. Contribution of Working Group I to the Fifth Assessment Report of the Intergovernmental Panel on Climate Change. United Kingdom, UK and New York, NY, USA. Ed. Cambridge University Press.

Paniagua, F. (2018). Empleo de $\mathrm{H}_{2} \mathrm{O}_{2}$ para la desinfección de soluciones de lixiviación empleadas en fertirrigación (Tesis de pregrado). Universidad de Almería, España.

Puente, R., Rochín, J., Valdéz, R., López, J. \& Huez, M.A. (2013). Evaluación de extracto de semillas de cítricos en el control de enfermedades foliares de tomate saladette indeterminado (Lycopersicum esculentum Mll var. Roma). XVI Congreso Internacional de Ciencias Agrícolas: Producción y Protección de cultivos bajo un escenario de cambio climático. Mexicali, Baja California, Mexico.

Salazar, E. (2005). Forraje verde hidropónico: una alternativa para la alimentación animal. Revista EGAG, 32, pp. 36-39.

Valls, S. \& Sáenz, C. (2015). Efecto del agua oxigenada en la germinación y el Ciclo AscorbatoGlutatión en plántulas de melón. IDIES: I+D en Institutos de Educación Superior. Recuperado de: https://www.idiesmurcia.es/proyects/pdf/p5 2015 efecto del agua oxigenada en la germinacion-pro.pdf 